\title{
28 Research Square \\ Experimental and Theoretical Approaches for Polyvinylchloride Enhanced with Metal Oxides/Graphene
}

Hend A. Ezzat

National Research Institute of Astronomy and Geophysics (NRIAG)

Maroof A. Hegazy

National Research Institute of Astronomy and Geophysics (NRIAG)

Ibrahim S. Yahia

Ain Shams University

Heba Y. Zahran

Ain Shams University

Hanan Elhaes

Ain Shams University

Medhat IBRAHIM ( $\square$ medahmed6@yahoo.com )

The British University in Egypt (BUE) https://orcid.org/0000-0002-1234-5431

\section{Research Article}

Keywords: PVC, ZnO, G, FTIR, XRD, SEM and DFT

Posted Date: January 24th, 2022

DOI: https://doi.org/10.21203/rs.3.rs-1276928/v1

License: (9) (i) This work is licensed under a Creative Commons Attribution 4.0 International License.

Read Full License 


\section{Abstract}

Introducing graphene $(\mathrm{G})$ into the polymer matrix is supposed to improve both the electrical and optical characteristics, especially in space applications. To study the effect of metal oxide and G on PVC, a matrix of $\mathrm{PVC} / \mathrm{ZnO} / \mathrm{G}$ nanocomposite was prepared and studied using different spectroscopic techniques. As a consequence, the Fourier Transform Infrared (FTIR) spectra for PVC/ZnO/G revealed two significant bands at $1596 \mathrm{~cm}^{-1}$ and $515 \mathrm{~cm}^{-1}, \mathrm{G}$ and $\mathrm{ZnO}$, respectively, confirming the composite synthesis. Also, X-ray Diffraction (XRD) and Field-emission Scanning Electron Microscopy (FESEM) result confirmed the interaction between PVC, ZnO, and G. Density functional theory (DFT) calculations were performed at B3LYPL/LAN2DZ on PVC nanocomposites with various metal oxides such as $\mathrm{MgO} \mathrm{SiO}_{2}$, $\mathrm{TiO}_{2}, \mathrm{NiO}, \mathrm{CuO}, \mathrm{ZnO}$, and $\mathrm{ZrO}_{2}$ and then reinforced with graphene quantum dots (GQDs). The findings of the HOMO/LUMO band gap energy, total dipole moment (TDM), and Molecular Electrostatic Potential (MESP) indicated that the effect of $\mathrm{MgO}$ in the presence of GQD gives a nanocomposite with high electronic characteristics with a TDM of 16.675 Debye $\Delta \mathrm{E} 0.231 \mathrm{eV}$. The distinctive properties of such nanocomposite PVC/MgO/GQD ZTRI C46 enabling usage in optical and electrical components and systems, as well as anti-reflection coating applications for solar cells.

\section{1- Introduction}

Polymer nanocomposites have recently gained interest for their ability to enhance polymer characteristics with low nanoparticle concentrations [1, 2]. PVC is one of the most versatile polymers, and modification and functionalization of PVC increase and change the polymer characteristics [3, 4]. Studies polymer optical and electrical characteristics gained recently much interest owing to its functionality in optical devices $[5,6]$. MOs, for example, are commonly used as nanofillers to improve the characteristics of polymers, lowering the cost of polymeric materials while enhancing their functionality [7-9]. The $\mathrm{PVC} / \mathrm{ZnO}$ nanocomposite demonstrated that $\mathrm{ZnO}$ increased the dielectric properties and mechanical and thermal stability [10] of insulating polymers, allowing them to be used in electrical applications [11]. Furthermore, the $\mathrm{PVC} / \mathrm{Fe}_{2} \mathrm{O}_{3}$ nanocomposite demonstrated higher mechanical properties confirming that adding $\mathrm{Fe}_{2} \mathrm{O}_{3}$ nanoparticles increased resistivity of the PVC polymer matrix [12]. $\mathrm{PVC}$ with $\mathrm{ZnO}, \mathrm{SiO}_{2}$, and $\mathrm{Al}_{2} \mathrm{O}_{3}$ enhance the refractive index materials appropriate to be used as solar cells anti-reflection cover and high refractive lenses applications, which could be adjusted by MOs type and content [13]. Moreover, increasing the number of $\mathrm{NiO}$ nanoparticles in the sample increases the impact nanoparticals on PVC matrix optical characteristics, suggesting these materials for electrical and photonic devices [14]. Moreover, theoretical calculations have recently been used to investigate chemical problems by studying molecular geometries [15, 16], molecule energies [17], infrared rays (IR) [18], and physical properties of structures [19]. There are several methods for investigating the materials chemical as well as physical properties that are often represent the organometallic interactions in addition to nanocomposites $[20,21]$. DFT is currently regarded as the optimum method for molecular structure model simulation [22, 23]. Furthermore, DFT gives higher accuracy result approximate to the experimental result [24, 25]. Moreover, DFT:B3LYP/LanL2DZ calculations of a PVC/PEO/SiC nanocomposite were performed to study electronic 
properties as well as spectroscopic features, revealed the ability of the new composite to utilized as optoelectronic material [26].

The objective of this study is to prepare a PVC/ZnO/G nanocomposite to investigate whether the molecular structure and morphology of the PVC surface are impacted. Furthermore, molecular modeling was used to investigate and evaluate the impact of $\mathrm{MO}$ nanoparticles on the electronic characteristics of PVC (MgO, $\mathrm{Al}_{2} \mathrm{O}_{3}, \mathrm{SiO}_{2}, \mathrm{TiO}_{2}, \mathrm{Fe}_{3} \mathrm{O}_{4}, \mathrm{NiO}, \mathrm{CuO}, \mathrm{ZnO}$, and $\mathrm{ZrO}_{2}$ ). To test the compatibility of the produced composites for optoelectronic applications, the TDM, band gap energy, and MESP were calculated. With the same parameters, the impact of doping GQDs on PVC/MOs nanocomposite was determined.

\section{2- Material And Methods:}

For composite preparation, high-molecular-weight PVC (Fluka \#81392), zinc (II) acetate dihydrate (Fisher chemical, 99\%), and sodium hydroxide (Fisher chemical, 97\%) were utilized. During this experiment, deionized water (DI) was used. Furthermore, no purifications were performed on any of the materials.

\section{2-1- Synthesis of ZnO Nanoparticles:}

Precipitation method was used to $\mathrm{ZnO}$ nanoparticles synthetizations. Firstly, zinc (II) acetate dissolved in DI $(100 \mathrm{~mL})$ at $70^{\circ} \mathrm{C}$. At that time $2 \mathrm{M}$ sodium hydroxide in $(100 \mathrm{~mL})$ DI water was prepared and added drop wisely while stirring. The white precipitate then filtrated and washed. Prepared $\mathrm{ZnO}$ dried at $80^{\circ} \mathrm{C}$ for $24 \mathrm{~h}$. finally the $\mathrm{ZnO}$ sample calcined for $2 \mathrm{~h}$ at $500^{\circ} \mathrm{C}$.

\section{2-2- Preparation of PVC/ZnO/G Composite:}

(70\%) of PVC was dissolved in $100 \mathrm{ml}$ of DI water then $(0.01 \mathrm{gm})$ of $\mathrm{ZnO}$ and $(0.02 \mathrm{gm})$ of $\mathrm{G}$ sheets were added to the solution after complete dissolve with stirring until a homogeneousness. Then putted at room temperature to dry.

\section{2-3- Analytical Techniques:}

All prepared samples were characterized using an Attenuated Total Reflection Fourier Transform Infrared (ATR-FTIR) with spectral range $4000-400 \mathrm{~cm}^{-1}$ as well as resolution of $4 \mathrm{~cm}^{-1}$ (Vertex 70 , Bruker) spectrometer to study the intermolecular structure. Then, X-ray Diffraction (XRD) was used to study the nanofiller impact on crystal structure as well as phase composition via a Malvern Panalytical Empyrean 3 diffractometer to study the and crystal structure of prepared samples. Finally, Field-emission Scanning Electron Microscopy was used to study the morphology of the prepared samples using (FESEM, Quattro $\mathrm{S}$, Thermo Scientific).

\section{2-4- Calculation Details:}

To investigate the influence of metal oxides on PVC electronic characteristics, a PVC model structure was interacted with $\mathrm{MO}$ such as $\mathrm{MgO}, \mathrm{Al}_{2} \mathrm{O}_{3}, \mathrm{SiO}_{2}, \mathrm{TiO}_{2}, \mathrm{Fe}_{3} \mathrm{O}_{4}, \mathrm{NiO}, \mathrm{CuO}, \mathrm{ZnO}$, and $\mathrm{ZrO}_{2}$. The GAUSSIAN09 [27] was used to compute all models at the Molecular Spectroscopy and Modeling Unit, National 
Research Centre, Egypt. For structural computations, the DFT:B3LYP/LANL2DZ model was used [28-30]. For all model structures, the TDM, HOMO/LUMO band gap, in addition to MESP surface representing were computed in order to examine electrical characteristics.

\section{3- Result And Discussion}

\section{3-1-PVC/ZnO/G Composite Experimental study:}

\section{a. FTIR Result:}

The FTIR spectra of pure PVC, ZnO, G, and PVC/ZnO/G composite are shown in figure (1). The PVC characteristic bands were shown as follows: the stretching vibration of $\mathrm{C}-\mathrm{H}$ occurred at $2914 \mathrm{~cm}^{-1}$ and $2970 \mathrm{~cm}^{-1}$. Sharp bands at $1426 \mathrm{~cm}^{-1}$ and $1264 \mathrm{~cm}^{-1}$ can thus be attributed to the bending vibrations of $\mathrm{CH}_{2}$ and $\mathrm{C}-\mathrm{H}$ in $\mathrm{CHCl}$, respectively. Finally, at $608 \mathrm{~cm}^{-1}$, the band related to the stretching vibration of $\mathrm{C}-\mathrm{Cl}$ was observed [31]. The $\mathrm{ZnO}$ nanoparticles are represented by the main band at $599 \mathrm{~cm}^{-1}$ according to the $\mathrm{ZnO}$ result [32]. The $\mathrm{PVC} / \mathrm{ZnO} / \mathrm{G}$ spectrum of shows the characteristic bands of pure PVC with the appearance of two strong bands at $1596 \mathrm{~cm}^{-1}$, representing the $\mathrm{C}-\mathrm{C}$ of $\mathrm{G}$ and a $\mathrm{ZnO}$ band shifted to a lower wavenumber at $515 \mathrm{~cm}^{-1}$ which confirmed the composite formation.

\section{b. XRD Result:}

The XRD analysis, illustrated in figure (2), which reflect the structure and composition for producing nanoparticles and nanocomposite. The XRD pattern of pure PVC shows the characteristic peak at $2 \theta=$ $17.00^{\circ}$ and $24.66^{\circ}$ related to diffraction planes (001) and (201), respectively [33]. The hexagonal wurtzite structure of $\mathrm{ZnO}$ nanoparticles is illustrated in XRD pattern where the crystalline peaks are shown at around $2 \theta=31.77^{\circ}, 34.42^{\circ}, 36.26^{\circ}, 47.54^{\circ}, 56.58^{\circ}, 62.86^{\circ}, 66.37^{\circ}, 67.96^{\circ}, 69.10^{\circ}, 72.53^{\circ}, 76.94^{\circ}$ and $81.467^{\circ}$ which related to the diffraction plans as (100), (002), (101), (102), (110), (103), (200), (112), (201), (202), and (104), respectively [34]. The $G$ characteristic peak is illustrated at $2 \theta=25.01^{\circ}$ with respect to the (002) diffraction plane. Furthermore, $\mathrm{PVC} / \mathrm{CuO} / \mathrm{G}$ peaks at $2 \theta=18.07^{\circ}, 24.47^{\circ}, 31.69^{\circ}$, $34.36^{\circ}, 36.19^{\circ}, 47.52^{\circ}, 56.57^{\circ}, 62.80^{\circ}, 67.89^{\circ}$, and $69.11^{\circ}$ related to (110), (201), (301), (120), (101), (102), (110), (103), (112), and (201) diffraction plane containing PEO, CUO and G characteristic peaks indicated that the composite was successfully formed.

\section{c. SEM Result:}

Figure (3) represents surface morphological images of PVC, ZnO, G, and PVC/ZnO/G nanocomposite at various magnifications to analyse the changes on the PVC surface. The SEM image of pure PVC shows the fractured surfaces of pure PVC to be comparatively smooth. The interaction of PVC with both ZnO and $\mathrm{G}$ results in the presence of $\mathrm{ZnO}$ nanoparticles [35]. In addition to this, the $\mathrm{G}$ sheets on the surfaces of nanocomposite samples are in the form of agglomerated structures. 
Based on the experimental findings, molecular modelling was used to investigate and evaluate the impact of $\left(\mathrm{MgO}, \mathrm{Al}_{2} \mathrm{O}_{3}, \mathrm{SiO}_{2}, \mathrm{TiO}_{2}, \mathrm{Fe}_{3} \mathrm{O}_{4}, \mathrm{NiO}, \mathrm{CuO}, \mathrm{ZnO}\right.$, and $\left.\mathrm{ZrO}_{2}\right)$ nanoparticles on the electronic properties of PVC in order to evaluate the atibility of the prepared composite for optoelectronic applications.

\section{d. Building Model Molecule}

Polymeric nanocomposite became essential owing to its wide variety of applications owing to the influence nanofillers have on the polymer matrix, which enhances the polymer matrix's essential features [36]. Therefore, four monomers of the PVC model structure are suggested to interact with a variety of MOs such as $\mathrm{MgO}, \mathrm{Al}_{2} \mathrm{O}_{3}, \mathrm{SiO}_{2}, \mathrm{TiO}_{2}, \mathrm{Fe}_{3} \mathrm{O}_{4}, \mathrm{NiO}, \mathrm{CuO}, \mathrm{ZnO}$, and $\mathrm{ZrO}_{2}$. Change in $\mathrm{HOMO} / \mathrm{LUMO}$ distribution as well as for MESP according to the interactions were studied, which is an important descriptor, to investigate the influence of MOs composition on the electronic properties of PVC.

\section{e. Interactions of PVC/Metal Oxides}

\section{HOMO/LUMO Orbital Distribution}

To represent the proposed study, four monomers of the PVC polymer chain interacted with different metal oxides such as $\mathrm{MgO}, \mathrm{Al}_{2} \mathrm{O}_{3}, \mathrm{SiO}_{2}, \mathrm{TiO}_{2}, \mathrm{Fe}_{3} \mathrm{O}_{4}, \mathrm{NiO}, \mathrm{CuO}, \mathrm{ZnO}$, and $\mathrm{ZrO}_{2}$. The change in $\mathrm{HOMO} / \mathrm{LUMO}$ distributions were studied, as shown in figure (4). The dispersion of HOMO/LUMO orbital in PVC is uniformly spread through the whole chain. However, HOMO/LUMO orbitals according to MOs interactions are redistributed and concentrated over MO atoms. Table (1) shows the computed TDM and band gap energy (E) values for model structures. The result of TDM showed that TDM increased for all PVC/MOs interactions from 7.302 Debye to 34.641, 18.634, 24.665, 08.842, 25.950, 34.179, 09.882, 23.417, 17.780, 26.714, 17.082, 31.949, 17.069 and 35.128 Debye for $\mathrm{MgO}, \mathrm{OMg}, \mathrm{Al}_{2} \mathrm{O}_{3}, \mathrm{O}_{3} \mathrm{Al}_{2}, \mathrm{SiO}_{2}, \mathrm{TiO}_{2}, \mathrm{Fe}_{3} \mathrm{O}_{4}, \mathrm{NiO}, \mathrm{ONi}$, $\mathrm{CuO}, \mathrm{OCu}, \mathrm{ZnO}, \mathrm{OZn}$ and $\mathrm{ZrO}_{2}$ respectively. Simultaneously, the band gap energy $(\Delta \mathrm{E})$ of $\mathrm{PVC} / \mathrm{MO}$ decreased from $5.479 \mathrm{eV}$ to $0.448,1.147,1.419,1.798,0.922,0.751,1.063,1.125,0.883,1.922,1.449$, 0.527, 1.512 and 0.767 for $\mathrm{MgO}, \mathrm{OMg}, \mathrm{Al}_{2} \mathrm{O}_{3}, \mathrm{O}_{3} \mathrm{Al}_{2}, \mathrm{SiO}_{2}, \mathrm{TiO}_{2}, \mathrm{Fe}_{3} \mathrm{O}_{4}, \mathrm{NiO}, \mathrm{ONi}, \mathrm{CuO}, \mathrm{OCu}, \mathrm{ZnO}, \mathrm{OZn}$ and $\mathrm{ZrO}_{2}$, respectively. As a result, the TDM rising in addition to reduce band gap energy $(\Delta \mathrm{E})$. As previously stated, increasing TDM with decreasing band gap energy $(\Delta \mathrm{E})$ enhanced the stability and electrical behavior of polymer matrix [37]. Consequently, $\mathrm{PVC} / \mathrm{MgO}$ is the most electronically enhanced and stable structure.

Table 1. Calculated TDM (Debye) and $\triangle \mathrm{E}(\mathrm{eV})$ using DFT:B3LYP/LANL2DZ of the PVC interaction with different metal oxides 


\begin{tabular}{|c|c|c|}
\hline Structure & TDM (Debye) & $\Delta \mathrm{E}(\mathrm{eV})$ \\
\hline PVC & 07.302 & 5.479 \\
\hline PVC/MgO & 34.641 & 0.448 \\
\hline PVC/OMg & 18.634 & 1.147 \\
\hline $\mathrm{PVC} / \mathrm{Al}_{2} \mathrm{O}_{3}$ & 24.665 & 1.419 \\
\hline $\mathrm{PVC} / \mathrm{O}_{3} \mathrm{Al}_{2}$ & 08.842 & 1.798 \\
\hline PVC/OSiO & 25.950 & 0.922 \\
\hline PVC/OTIO & 34.179 & 0.751 \\
\hline $\mathrm{PVC} / \mathrm{Fe}_{3} \mathrm{O}_{4}$ & 09.882 & 1.063 \\
\hline PVC/NiO & 23.417 & 1.125 \\
\hline PVC/ONi & 17.780 & 0.883 \\
\hline PVC/CuO & 26.714 & 1.922 \\
\hline $\mathrm{PVC} / \mathrm{OCu}$ & 17.082 & 1.449 \\
\hline PVC/Zno & 31.949 & 0.527 \\
\hline PVC/OZn & 17.069 & 1.512 \\
\hline PVC/OZro & 35.128 & 0.767 \\
\hline
\end{tabular}

Molecular Electrostatic Potential (MESP):

MESP stands as useful model representing the chemical structures electrostatic interactions with each other. The representation with reference to sequence of colors arranged as Red, Orange, Yellow, Green, and Blue, respectively. MESP colors mainly utilized to explore the structure sensitivity, reactivity besides stability. The importance of using MESP that it studies the influence of charge distribution changes on the structure's electronegativity, dipole moment, band gap, and chemical active sides [38]. Figure (5) shows the MESP of PVC and PVC reacted with several MOs, including $\mathrm{MgO}, \mathrm{Al}_{2} \mathrm{O}_{3}, \mathrm{SiO}_{2}, \mathrm{TiO}_{2}, \mathrm{Fe}_{3} \mathrm{O}_{4}, \mathrm{NiO}$, $\mathrm{CuO}, \mathrm{ZnO}$, and $\mathrm{ZrO}_{2}$. On the MESP surface, the greatest charge region represented in red colour, the lowest charge region represented via blue colour, besides the zero electrostatic potential region defined by green denotes. The highest potential is often found in red locations, whereas the poorest potential is frequently seen in blue parts. The $\mathrm{Cl}$ atom was discovered to be the centre of active PVC reactivity. When PVC interacted with different MOs, the red colour diffused across the polymer chain's up and down terminals, showing that PVC reactivity increased, and MOs reinforced PVC's active sides. In PVC/ MOs interaction through the metal atom, the red colour of low potential located primarily around the MO oxygen atom, whereas in case of PVC/ MOs interaction through oxygen atom, red colon redistributed through polymer 
chain besides expanded across the opposite side of PVC chain. Accordingly, PVC's electrical properties have increased, and it now could be used for numerous applications.

\section{b. GQDs Interaction with PVC/MgO:}

GQDs have a surface area for interaction, as well as having good edge atoms to interact other structures [39]. Furthermore, the bandgap adjusting feature and electron transport capacity of GQDs with varying sizes may be used in nanoelectronics devices and as optoelectronic materials [40]. As a result, $P V C / M O / G Q D$, in its four forms: ATRI, AHEX, ZTRI, and ZHEX, was created to combine with the highest $\mathrm{PVC} / \mathrm{MO}$ enhanced structure. For the suggested structures, HOMO/LUMO orbital distributions and MESP mapping were also investigated. As shown by investigation, $\mathrm{PVC} / \mathrm{MgO}$ was the chemically stable and active structure. PVC/MgO suggested to study the effect of four GQD forms the interaction as shown in figure (6). The band gap of PVC/MgO in table (2) decreased from $0.448 \mathrm{eV}$ to $0.382,0.324,0.231$, and $0.344 \mathrm{eV}$ for PVC/MgO/GQD ATRI C60, PVC/MgO/GQD AHEX C42, PVC/MgO/GQD ZTRI C46, and $\mathrm{PVC/MgO/GQD} \mathrm{ZHEX} \mathrm{C54,} \mathrm{respectively.} \mathrm{As} \mathrm{a} \mathrm{result,} \mathrm{PEO/CuO/GQD} \mathrm{ZTRI} \mathrm{C46} \mathrm{is} \mathrm{the} \mathrm{most} \mathrm{effective,} \mathrm{stable,}$ and unique in electrical characteristics antireflection coating applicants

Table 2. Calculated TDM (Debye) and $\triangle E(e V)$ using B3LYP/LANL2DZ of the PVC/MgO interactions with GQDs

\begin{tabular}{|lll|}
\hline Structure & TDM (Debye) & $\Delta \mathrm{E}(\mathrm{eV})$ \\
\hline PVC/MgO/ GQD ATRI C60 & 25.445 & 0.382 \\
\hline PVC/MgO/ GQD AHEX C42 & 24.652 & 0.324 \\
\hline PVC/MgO/ GQD ZTRI C46 & 16.675 & 0.231 \\
\hline PVC/MgO/ GQD ZHEX C54 & 21.846 & 0.344 \\
\hline
\end{tabular}

\section{4- Conclusion}

A PVC/ZnO/G composite was synthesized and investigated using ATR-FTIR, XRD, and FESEM. The presence of the two significant bands of $\mathrm{G}$ and $\mathrm{ZnO}$ in the spectrum verified the production of $\mathrm{PVC} / \mathrm{ZnO} / \mathrm{G}$. Moreover, SEM images reflect the effect of $\mathrm{ZnO}$ and $\mathrm{G}$ on the PVC surface. The type and concentration of MOs in the PVC matrix might modify its electrical and optical properties and control the band gap. The TDM, HOMO/LUMO and MESP results could be used to predict the properties of such nanocomposites for use in optical components and devices. Furthermore, the PVC/MgO/GQDs composite improved PVC's electrical and optical properties. The composite PVC/MgO/ GQD ZTRI C46 effect on PVC characteristics to operate as an anti-reflection coating application for solar cell nanocomposites, which is important in space applications.

\section{Declarations}




\section{Acknowledgments}

The authors extend their appreciation to the Deputyship for Research \& Innovation, Ministry of Education, in Saudi Arabia, for funding this research work through the project number: (IFP-KKU-2020/10).

\section{References}

1. K. Sterky, H. Jacobsen, I. Jakubowicz, N. Yarahmadi, T. Hjertberg, Influence of processing technique on morphology and mechanical properties of PVC nanocomposites. Eur. Polymer J. 46(6), 12031209 (2010)

2. M.K. Pal, B. Singh, J. Gautam, Thermal stability and UV-shielding properties of polymethyl methacrylate and polystyrene modified with calcium carbonate nanoparticles. J. Therm. Anal. Calorim. 107(1), 85-96 (2012)

3. A. Thabet, Y.A. Mubarak, M. Bakry, A review of nano-fillers effects on industrial polymers and their characteristics. Journal of Engineering Sciences 39, 377-403 (2011)

4. A. Aruniit, J. Kers, J. Majak, A. Krumme, K. Tall, 2012. Influence of hollow glass microspheres on the mechanical and physical properties and cost of particle reinforced polymer composites. Proceedings of the Estonian Academy of Sciences, 61, 160

5. S. Moulay, Chemical modification of poly (vinyl chloride) -Still on the run. Prog. Polym. Sci. 35(3), 303-331 (2010)

6. A. Thabet, A.A. Ebnalwaled, Improvement of surface energy properties of PVC nanocomposites for enhancing electrical applications. Measurement 110, 78-83 (2017)

7. T.A. Taha, Optical and thermogravimetric analysis of $\mathrm{Pb}_{3} \mathrm{O}_{4} / \mathrm{PVC}$ nanocomposites. J. Mater. Sci.: Mater. Electron. 28(16), 12108-12114 (2017)

8. O.G. Abdullah, S.B. Aziz, M.A. Rasheed, Effect of silicon powder on the optical characterization of Poly (methyl methacrylate) polymer composites. J. Mater. Sci.: Mater. Electron. 28(5), 4513-4520 (2017)

9. M. Bhattacharya, Polymer nanocomposites-a comparison between carbon nanotubes, graphene, and clay as nanofillers. Materials 9, 262 (2016)

10. M. Hajibeygi, M. Maleki, M. Shabanian, F. Ducos, H. Vahabi, New polyvinyl chloride (PVC) nanocomposite consisting of aromatic polyamide and chitosan modified $\mathrm{ZnO}$ nanoparticles with enhanced thermal stability, low heat release rate and improved mechanical properties. Appl. Surf. Sci. 439, 1163-1179 (2018)

11. S.A. Mansour, R.A. Elsad, M.A. Izzularab, Dielectric properties enhancement of PVC nanodielectrics based on synthesized ZnO nanoparticles. J. Polym. Res. 23(5), 1-8 (2016)

12. E. Demirel, B. Zhang, M. Papakyriakou, S. Xia, Y. Chen, Fe2O3 nanocomposite PVC membrane with enhanced properties and separation performance. J. Membr. Sci. 529, 170-184 (2017) 
13. A.A. Ebnalwaled, A. Thabet, Controlling the optical constants of PVC nanocomposite films for optoelectronic applications. Synth. Met. 220, 374-383 (2016)

14. T.A. Taha, N. Hendawy, S. El-Rabaie, A. Esmat, M.K. El-Mansy, Effect of NiO NPs doping on the structure and optical properties of PVC polymer films. Polym. Bull. 76(9), 4769-4784 (2019)

15. M.A. Ibrahim, A.E.D.A. Gawad, Spectroscopic analyses of chitosan interactions with amino acids. J. Comput. Theor. Nanosci. 9(8), 1120-1124 (2012)

16. A. Refaat, M.A. Ibrahim, H. Elhaes, R. Badry, H. Ezzat, I.S. Yahia, H.Y. Zahran, M. Shkir, Geometrical, vibrational and physical properties of polyvinyl chloride nanocomposites: Molecular modeling approach. Journal of Theoretical and Computational Chemistry 18(08), 1950037 (2019)

17. M. Ibrahim, Molecular modeling and FTIR study for $\mathrm{K}, \mathrm{Na}, \mathrm{Ca}$ and $\mathrm{Mg}$ coordination with organic acid. J. Comput. Theor. Nanosci. 6(3), 682-685 (2009)

18. H.A. Ezzat, M.A. Hegazy, N.A. Nada, O. Osman, M.A. Ibrahim, Development of natural polymer/metal oxide nanocomposite reinforced with graphene oxide for optoelectronic applications. NRIAG J. Astron. Geophys. 10(1), 10-22 (2021)

19. M.A. Hegazy, R. Ghoneim, H.A. Ezzat, I.S. Yahia, H. Elhaes, M.A. Ibrahim, Electronic and physical studies for Teflon FEP as a thermal control in low earth orbit reinforced with $\mathrm{ZnO}$ and $\mathrm{SiO} 2$ nanoparticles. J. Mol. Model. 27(10), 1-8 (2021)

20. A.A. Menazea, H.A. Ezzat, W. Omara, O.H. Basyouni, S.A. Ibrahim, A.A. Mohamed, W. Tawfik, M.A. Ibrahim, Chitosan/graphene oxide composite as an effective removal of $\mathrm{Ni}, \mathrm{Cu}, \mathrm{As}, \mathrm{Cd}$ and $\mathrm{Pb}$ from wastewater. Comput. Theor. Chem. 1189, 112980 (2020)

21. R. Badry, S.H. Radwan, D. Ezzat, H. Ezzat, H. Elhaes, M. Ibrahim, Study of the Electronic Properties of Graphene Oxide/(PANi/Teflon). Biointerface Research in Applied Chemistry 10, 6926-6935 (2020)

22. R. Badry, A. Ibrahim, F. Gamal, D. Shehata, H. Ezzat, H. Elhaes, M. Ibrahim, Electronic Properties of Polyvinyl Alcohol/TiO2/SiO2 Nanocomposites. Biointerface Research of Applied Chemistry 10, 6427-6435 (2020)

23. M. Ibrahim, Modeling the Effect of Zinc Oxide on the Electronic Properties of Polyvinyl Alcohol. Egypt. J. Chem. 63(12), 3-5 (2020)

24. M. Ibrahim, O. Osman, Spectroscopic analyses of cellulose: Fourier transform infrared and molecular modelling study. J. Comput. Theor. Nanosci. 6(5), 1054-1058 (2009)

25. F. Gomaa, O. Osman, H. Ezzat, M. Ibrahim, Molecular spectroscopic analyses of soil close to Nile Delta region. Quantum Matter 5(2), 263-267 (2016)

26. H. Ahmed, A. Hashim, 2020. Geometry optimization, optical and electronic characteristics of novel PVC/PEO/SiC structure for electronics applications. Silicon, 1-6.https://doi.org/10.1007/s12633020-00620-0

27. M.J. Frisch, G.W. Trucks, H.B. Schlegel, G.E. Scuseria, M.A. Robb, J.R. Cheeseman, G. Scalmani, V. Barone, B. Mennucci, G.A. Petersson, H. Nakatsuji, M. Caricato, X. Li, H.P. Hratchian, A.F. Izmaylov, J. Bloino, G. Zheng, J.L. Sonnenberg, M. Hada, M. Ehara, K. Toyota, R. Fukuda, J. Hasegawa, M. Ishida, T. Nakajima, Y. Honda, O. Kitao, H. Nakai, T. Vreven, J.A. Montgomery Jr., J.E. Peralta, F. Ogliaro, M. 
Bearpark, J.J. Heyd, E. Brothers, K.N. Kudin, V.N. Staroverov, T. Keith, R. Kobayashi, J. Normand, K. Raghavachari, A. Rendell, J.C. Burant, S.S. Iyengar, J. Tomasi, M. Cossi, N. Rega, J.M. Millam, M. Klene, J.E. Knox, J.B. Cross, V. Bakken, C. Adamo, J. Jaramillo, R. Gomperts, R.E. Stratmann, 0. Yazyev, A.J. Austin, R. Cammi, C. Pomelli, J.W. Ochterski, R.L. Martin, K. Morokuma, V.G. Zakrzewski, G.A. Voth, P. Salvador, J.J. Dannenberg, S. Dapprich, A.D. Daniels, O. Farkas, J.B. Foresman, J.V. Ortiz, J. Cioslowski, D.J. Fox, Gaussian 09, Revision C.01, Gaussian, Inc., Wallingford, CT, 2010

28. A.D. Becke, Density-functional thermochemistry. III. The role of exact exchange. J. Chem. Phys. 98, 5648-5652 (1993)

29. C. Lee, W. Yang, R.G. Parr, Development of the Colic-Salvetti correlation-energy formula into a functional of the electron density. Phys. Rev. B 37, 785 (1988)

30. S.H. Vosko, L. Wilk, M and Nusair, Accurate spin-dependent electron liquid correlation energies for local spin density calculations: a critical analysis. J. Phys. 58, 1200-1211 (1980)

31. S. Ramesh, M.F. Chai, Conductivity, dielectric behavior and FTIR studies of high molecular weight poly(vinylchloride)-lithium triflate polymer electrolytes. Mater. Sci. Eng.: B 139, 240-245 (2007)

32. M.A. Hegazy, H.H. El-Agamy, ICMMS-2: Synthesis and Characterization of ZnO Nanoparticles in Presence of Triethanolamine (TEA) as Surfactant Via Sol-Gel. Egypt. J. Chem. 64(3), 1207-1212 (2021)

33. A.A. Al-Muntaser, A.M. Abdelghany, E.M. Abdelrazek, A.G. Elshahawy, Enhancement of optical and electrical properties of PVC/PMMA blend films doped with Li4Ti5012 nanoparticles. Journal of Materials Research and Technology 9(1), 789-797 (2020)

34. R.P. Singh, V.K. Shukla, R.S. Yadav, P.K. Sharma, P.K. Singh, A.C. Pandey, Biological approach of zinc oxide nanoparticles formation and its characterization. Adv. Mater. Lett. 2, 313-317 (2011)

35. M. Dastpaki, H.A. Khonakdar, Thermal, thermomechanical, and morphological characterization of poly (vinyl chloride)(PVC)/ZnO nanocomposites: PVC molecular weight effect. J. Vinyl Add. Tech. 25(s2), E63-E71 (2019)

36. A. Hashim, A. Hadi, Synthesis and characterization of ( $\mathrm{MgO}-\mathrm{Y} 2 \mathrm{O} 3-\mathrm{CuO})$ nanocomposites for novel humidity sensor application. Sens. Lett. 15(10), 858-861 (2017)

37. Z. Al-Fifi, M. Eid, N.A. Saleh, M. Ibrahim, Molecular Modelling Analyses of the Substituted 3'-Azido-2', 3' Dideoxythymidine. J. Comput. Theor. Nanosci. 11(2), 409-412 (2014)

38. Z. Zhang, J. Zhang, N. Chen, L. Qu, Graphene quantum dots: an emerging material for energy/related applications and beyond. Energy Environ. Sci. 5(8890), 8869 (2012). 10.1039/C2EE22982J

39. P. Politzer, P.R. Laurence, K. Jayasuriya, Molecular electrostatic potentials: an effective tool for the elucidation of biochemical phenomena. Environ. Health Perspect. 61, 191-202 (1985)

40. J. Feng, H. Dong, B. Pang, Y. Chen, L. Yu, L. Dong, Tuning the electronic and optical properties of graphene quantum dots by selective boronization. J. Mater. Chem. C 7, 237-246 (2019). 10.1039/C8TC03863E

\section{Figures}




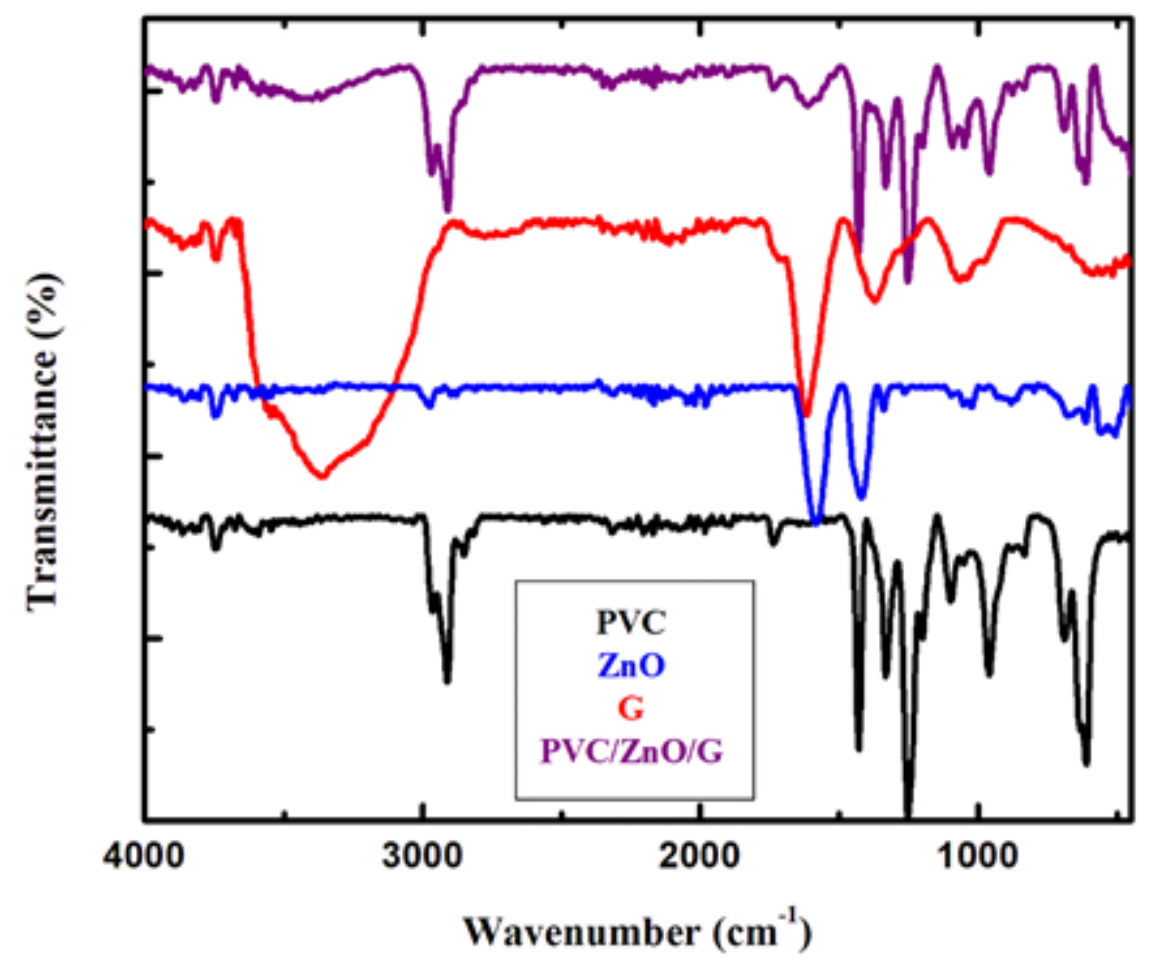

Figure 1

The ATR-FTIR transmittance result for PVC, ZnO, G and PVC/ZnO/G composite

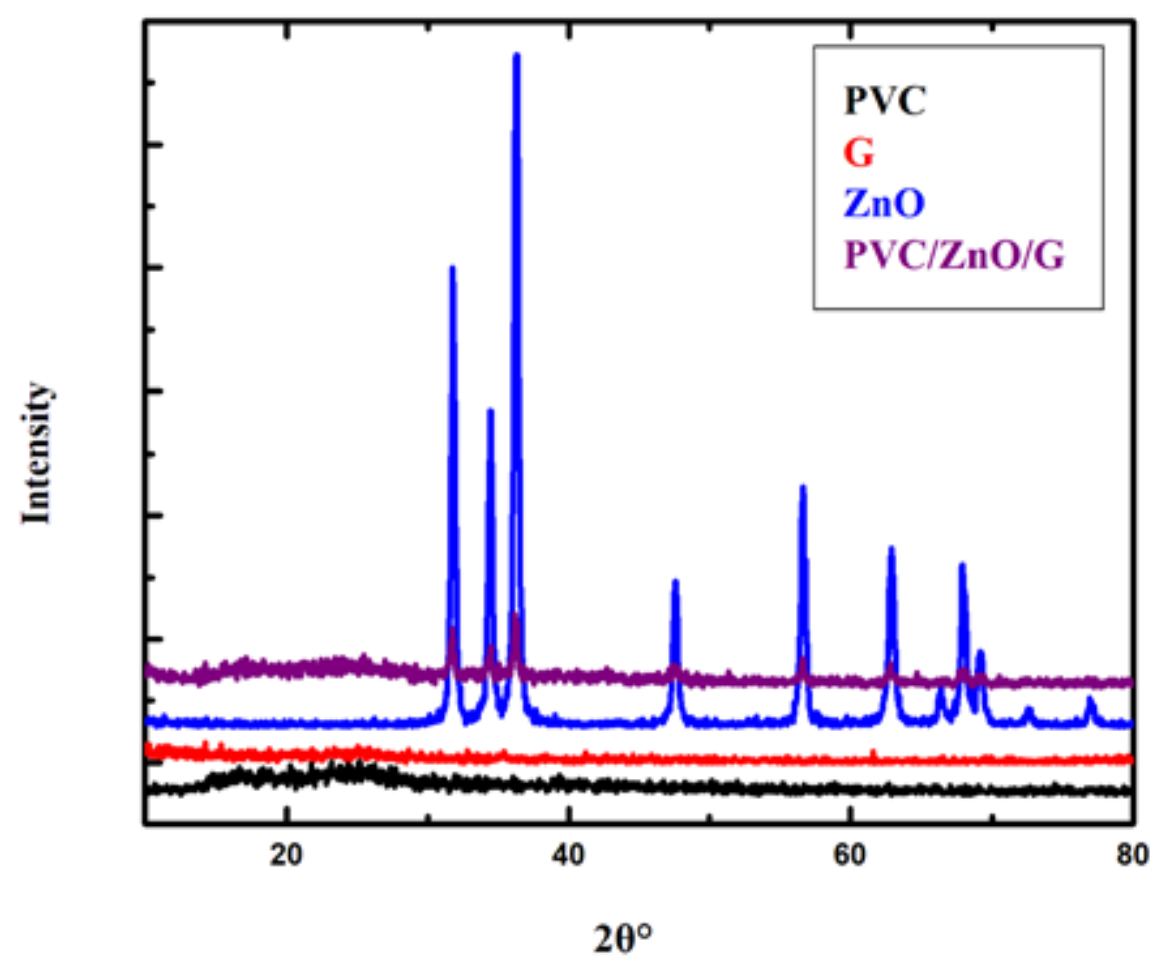

Figure 2 
XRD diffraction pattern for PVC, ZnO, graphene (G) and PVC/ZnO/G nanocomposite.

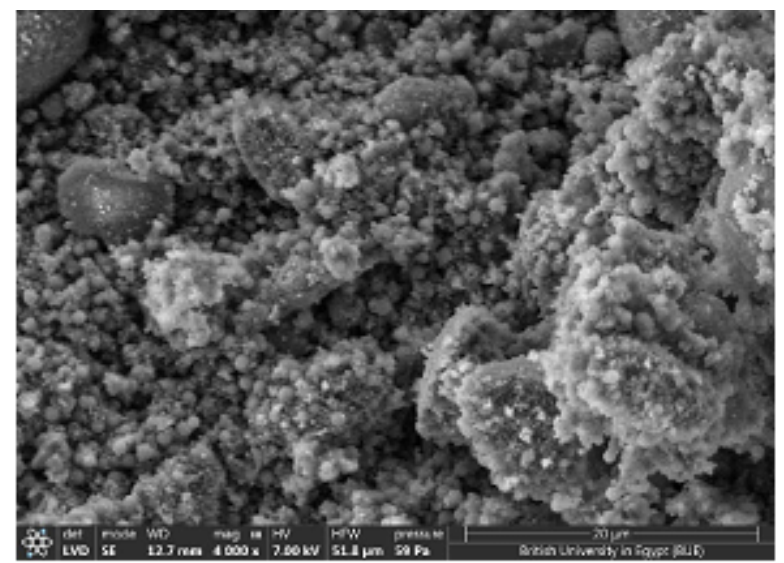

PVC

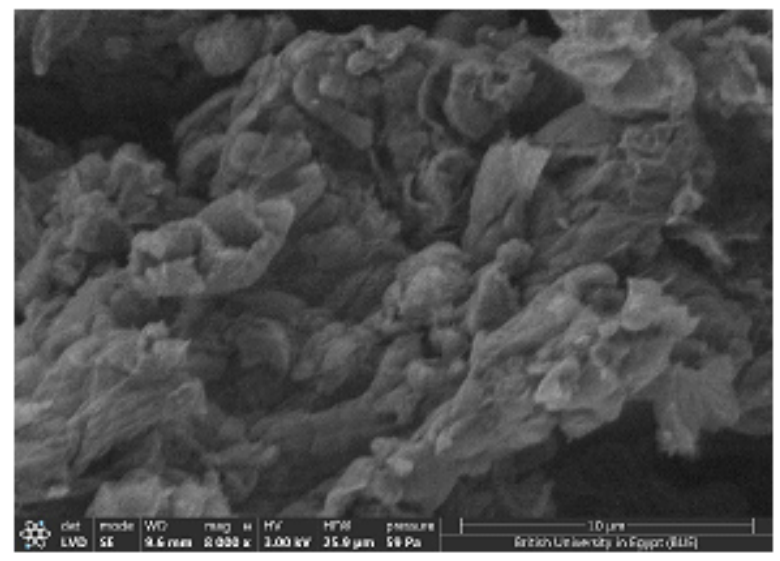

G

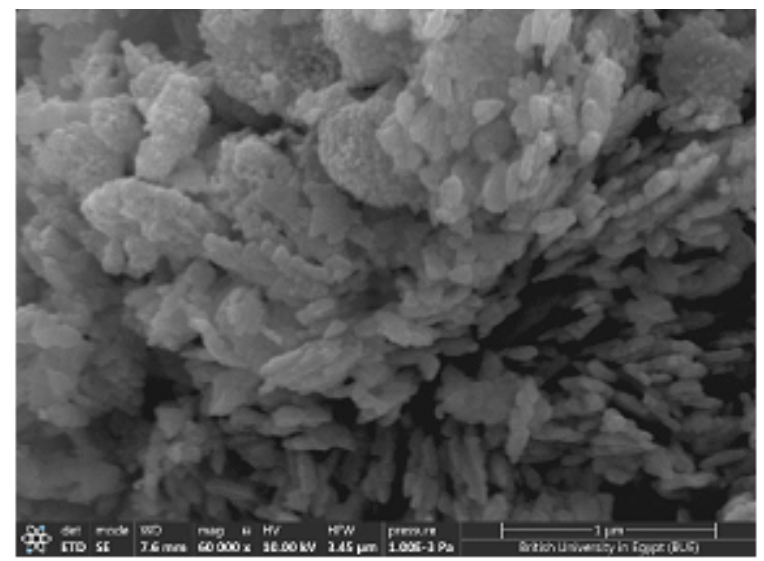

$\mathrm{ZnO}$,

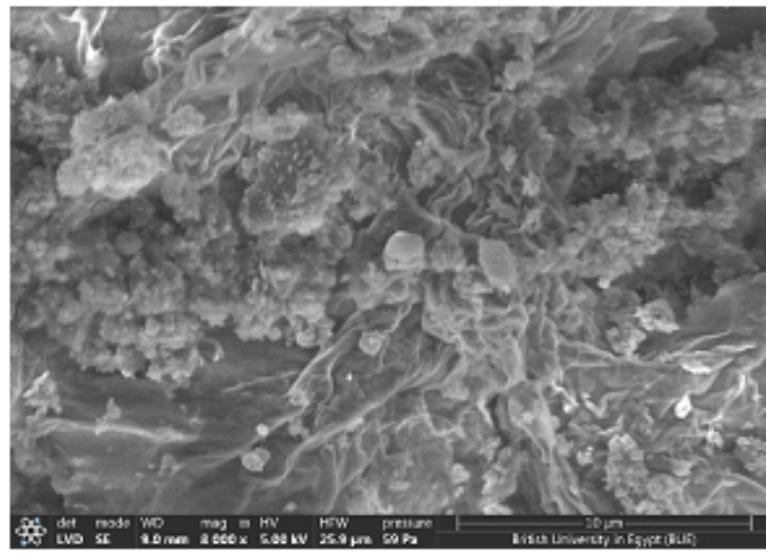

$\mathrm{PVC} / \mathrm{ZnO} / \mathrm{G}$

\section{Figure 3}

FESEM images with different magnifications for PVC, ZnO, G and PVC/ZnO/G composite

\section{Figure 4}

DFT:B3LYP/LANL2DZ of PVC and PVC interacted with different metal oxides HOMO-LUMO calculations and its optimized structure as
(a) PVC
(b) $\mathrm{PVC} / \mathrm{MgO}$
(c) $\mathrm{PVC} / \mathrm{OMg}$
(d) $\mathrm{PVC} / \mathrm{Al}_{2} \mathrm{O}_{3}$
(e) $\mathrm{PVC} / \mathrm{O}_{3} \mathrm{Al}_{2}$
(f) $\mathrm{PVC} / \mathrm{SiO}_{2}$
(g) $\mathrm{PVC} / \mathrm{TiO}_{2}$
(h) $\mathrm{PVC} / \mathrm{Fe}_{3} \mathrm{O}_{4}$
(i) $\mathrm{PVC} / \mathrm{NiO}$
(j)PVC/ONi 
$\begin{array}{lllll}\text { (k)PVC/CuO (l) PVC/OCu } & \text { (m)PVC/ZnO } & \text { (n)PVC/OZn } & \text { (o) } \mathrm{PVC} / \mathrm{ZrO}_{2}\end{array}$

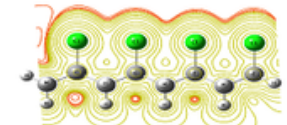

(a)

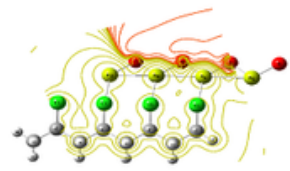

(b)

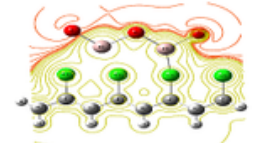

(d)

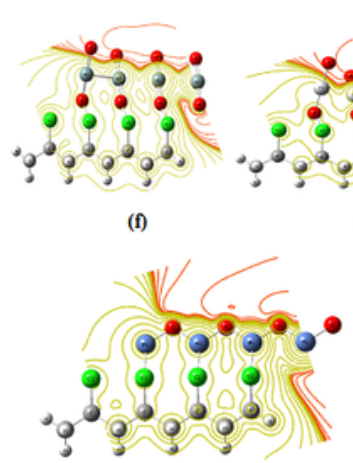

(i)

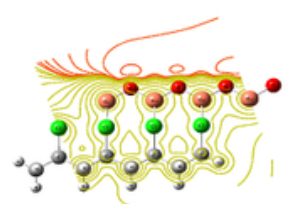

(k)

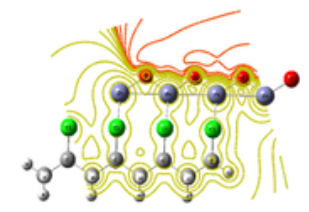

(m)

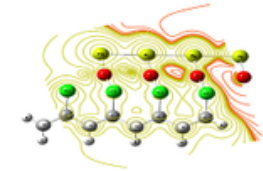

(c)

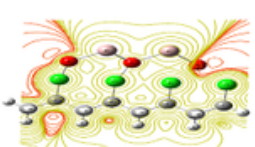

(e)

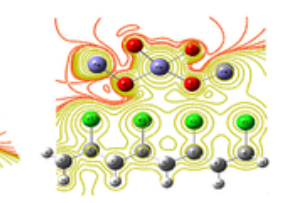

(h)

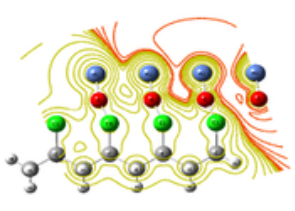

(j)

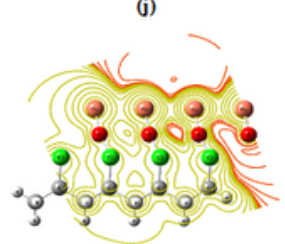

(I)

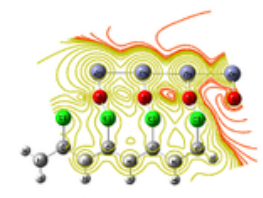

(n)

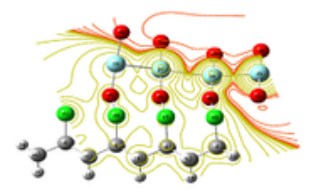

(o)

Figure 5

DFT:B3LYP/LANL2DZ of PVC and PVC interacted with different metal oxides MESP mapping as
(a) PVC
(b) $\mathrm{PVC} / \mathrm{MgO}$
(c) $\mathrm{PVC} / \mathrm{OMg}$
(d) $\mathrm{PVC} / \mathrm{Al}_{2} \mathrm{O}_{3}$
(e) $\mathrm{PVC} / \mathrm{O}_{3} \mathrm{Al}_{2}$ 

(f) $\mathrm{PVC} / \mathrm{SiO}_{2}$
(g) $\mathrm{PVC} / \mathrm{TiO}_{2}$
(h) PVC/ $\mathrm{Fe}_{3} \mathrm{O}_{4}$
(i) $\mathrm{PVC} / \mathrm{NiO}$
(j) $\mathrm{PVC} / \mathrm{ONi}$
(k) PVC/CuO
(I) $\mathrm{PVC} / \mathrm{OCu}$
(m) PVC/Zno
(n) PVC/OZn
(o) $\mathrm{PVC} / \mathrm{ZrO}_{2}$
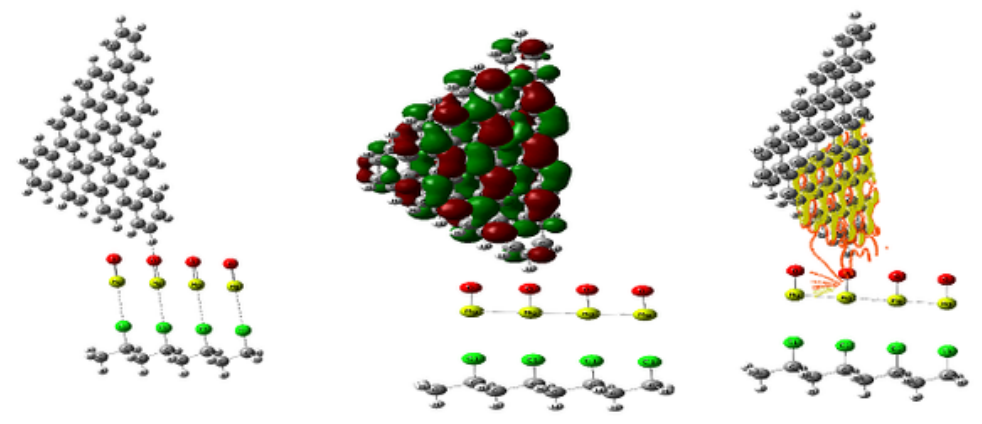

(a)
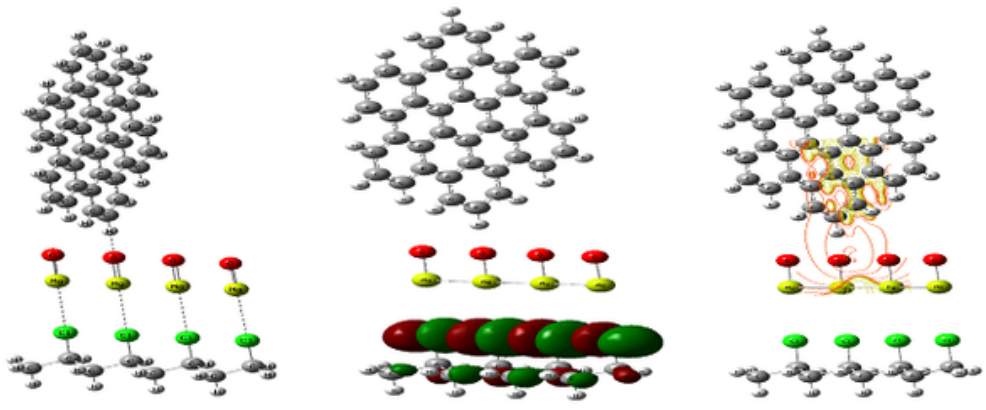

(b)
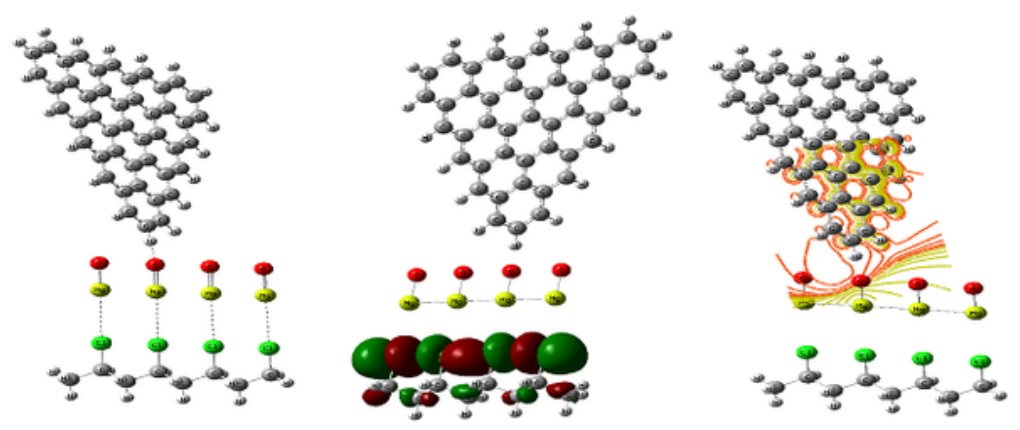

(c)
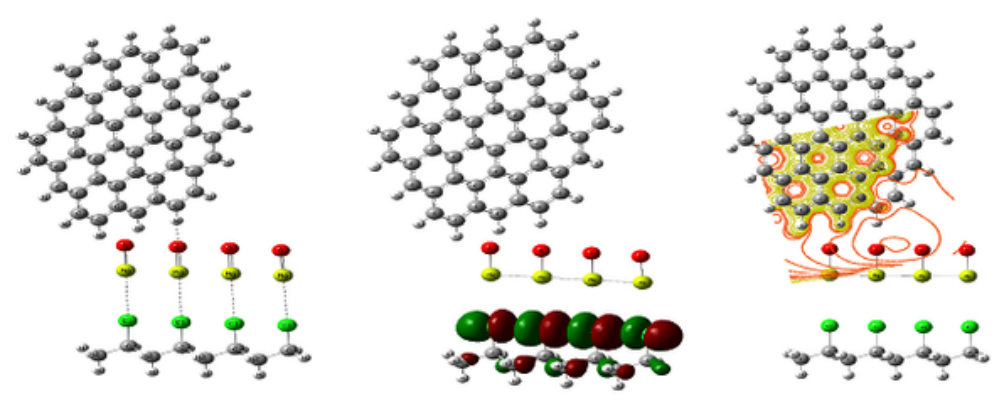

(d)

Figure 6 
DFT:B3LYP/LANL2DZ calculations for optemized structure and HOMO/LUMO orbital distrbution and MESP as contour of the PV/MgO interactions with GQDs as
(a) $\mathrm{PVC} / \mathrm{MgO} / \mathrm{GQD}$ ATRI C60
(b) PVC/MgO/GQD AHEX C42
(c) $\mathrm{PVC} / \mathrm{MgO} / \mathrm{GQD}$ ZTRI C46
(d) PVC/MgO/GQD ZHEX C54 